\title{
Head-Worn Displays for NextGen
}

\author{
Randall E. Bailey, Kevin J. Shelton and J.J. (Trey) Arthur, III \\ NASA Langley Research Center, Hampton, VA
}

\begin{abstract}
The operating concepts emerging under the Next Generation air transportation system (NextGen) require new technology and procedures - not only on the ground-side - but also on the flight deck. Flight deck display and decision support technologies are specifically targeted to overcome aircraft safety barriers that might otherwise constrain the full realization of NextGen. One such technology is the very lightweight, unobtrusive head-worn display (HWD). HWDs with an integrated head-tracking system are being researched as they offer significant potential benefit under emerging NextGen operational concepts. Two areas of benefit for NextGen are defined. First, the HWD may be designed to be equivalent to the Head-Up Display (HUD) using Virtual HUD concepts. As such, these operational credits may be provided to significantly more aircraft for which HUD installation is neither practical nor possible. Second, the HWD provides unique display capabilities, such as an unlimited field-of-regard. These capabilities may be integral to emerging NextGen operational concepts, eliminating safety issues which might otherwise constrain the full realization of NextGen. The paper details recent research results, current HWD technology limitations, and future technology development needed to realize HWDs as a enabling technology for NextGen.
\end{abstract}

Keywords: Head-Worn Display, Head-Up Display, Enhanced Vision, Synthetic Vision, Latency

\section{INTRODUCTION}

Although today's National Airspace System (NAS) is one of the safest means of transportation, it has evolved into a large, complex, and loosely integrated network of systems that is especially prone to delays cascading throughout the system because of adverse weather conditions. The Next Generation Air Transportation System (NextGen) concept for the year 2025 and beyond envisions the movement of large numbers of people and goods in a safe, efficient, and reliable manner. The goal of NextGen is to remove many of the constraints in the current air transportation system, support a wider range of operations, and deliver significantly increased system capacity to that of current operating levels. Operating concepts emerging under NextGen require new technology and procedures - not only on the ground-side - but also on the flight deck. One of the key elements is to create a NAS that is resilient, if not immune to the impacts of weather.

National Aeronautics and Space Administration (NASA) research, development, test, and evaluation (RDT\&E) of flight deck interface technologies is being conducted to proactively overcome aircraft safety barriers that might otherwise constrain the full realization of NextGen. As part of this work, specific research issues associated with the NextGen Terminal Maneuvering Area (TMA) are being addressed. This paper summarizes research and technology development being conducted by NASA and its partners investigating the use of Head-Worn Displays (HWDs) as a NextGen enabling technology for fixed-wing aircraft.

\section{BACKGROUND}

The idea of weather-immunity for NextGen is captured in many respects within the emerging operational concept entitled Equivalent Visual Operations (EVO). The goal of EVO is to create Visual Flight Rules (VFR)-like operational tempos and VFR-like safety, in all weather conditions. At many locations, such as Chicago O'Hare airport, when weather requires the use of Instrument Flight Rules (IFR) operations today, arrival throughput capacity drops from eight arrivals every five minutes down to five arrivals every five minutes (Vasquez-Marquez, 1991). The delays associated with IFR restrictions depend upon the air traffic mix and airport runway configuration, but more often, the change from

\footnotetext{
Randall.E.Bailey@nasa.gov, NASA LaRC, 24 W Taylor Street, Hampton, VA 23681, phone 757-864-8682
} 
VFR to IFR operations can be dramatic (FAA, 1983). Because of the NAS interconnectivity, operational delays at one airport cascade throughout the NAS.

EVO implies Category III operations to all runway ends (e.g., a decision height (DH) lower than $100 \mathrm{ft}$, or no decision height, or a runway visual range (RVR) less than $1200 \mathrm{ft}$ ). Landing in near zero visibility conditions is not new or novel. Automatic and manual landing systems are certified and operational down to $300 \mathrm{ft}$ RVR. Unfortunately, the cost to develop, maintain, and train the crew and aircraft with these systems can be cost prohibitive. For instance, there are only 126 Category III approaches in the NAS (Kramer et al, 2007) - well short of accommodating the 19,800 airports in the NAS (FAA, 2007). The 20 year life cycle costs for just the required Category III-type approach lighting system alone is more than $\$ 5.4 \mathrm{M}$ at each runway end (Kramer et al, 2008). Using today's Category III landing systems and operating rules throughout the NAS is just not a practical solution for weather-immunity.

Even with all-weather auto-land systems, previous research has shown that, while the capability may be available to take-off and land aircraft in near zero visibility, operational tempos and safety are significantly degraded, compared to VFR, due to limitations in surface operations - that is, taxiing and maneuvering aircraft and vehicles to/from the active runways and gates (Chin, 1997). Auto-land systems may provide some aspects of EVO, but other technologies are needed to fulfill the full promises of NextGen.

For this reason, Synthetic / Enhanced Vision Systems (SEVS), in addition to other technologies, are being viewed as 'enabling NextGen' avionics to provide 'greater access and throughput at airports' (JPDO, 2008). SEVS are "visionbased" technologies intended to create, supplement, or enhance the natural vision of the pilot (Kramer et al, 2008). Enhanced Flight Vision Systems (EFVS) - a certified and approved enhanced vision system used on a Head-Up Display (HUD) - enable a pilot to continue descent below the published DH in lieu of the pilot's natural vision view of the approach and landing visual references. Synthetic vision is a computer-generated image of the external scene topography that is generated from aircraft attitude, high-precision navigation, and data of the terrain, obstacles, cultural features, and other required flight information. These two technologies are complementary and, when combined, the potential for all-weather operations using an electronic means of providing the pilot with an "equivalent vision capability" are realizable (Bailey, Kramer, Prinzel, 2005).

The emerging vision-based technologies of SEVS and the need and emergence of new NextGen operational concepts may create two motivations (or market segments) for the introduction of the HWD into commercial and business aviation: 1) equivalent HUD capabilities; and 2) new NextGen operational capabilities.

\section{EQUIVALENT HUD CAPABILITIES}

The advantages of a HUD in commercial and business aircraft operations are many, but two hold particular appeal:

- The conformal display of critical flight parameters/symbology increases safety by reducing the visual accommodation and re-accommodation that the pilot would otherwise have between reading head-down instrumentation and transitioning to out-the-window visual references during operations such as approach, landing, taxiing, and take-off. The safety benefits of the HUD were recently quantified (Flight Safety Foundation, 2009). The study found that HUDs prevented or positively influenced $38 \%$ of accidents overall in modern glass cockpits. Of those accidents where the pilot was directly involved, such as takeoff or loss-ofcontrol, the "safety advantage" of the HUD became much higher ( $69 \%$ and $57 \%$, respectively).

- The explicit display of flight path and energy information on the HUD promotes precision touchdown capability and energy management - i.e., maximizing landing performance (minimizing aircraft wear-and-tear). Studies show that significantly lower touchdown sink rates are flown under manual than automatic landings (Rustenburg, Tipps, and Skinn, 2001) and experimental evidence show that the HUD promotes better sink rate control and touchdown performance (Bailey, Kramer, and Williams, 2010; Kramer et al, 2011).

Despite these advantages, the introduction of HUDs in the commercial and business aircraft fleet took considerable time. HUDs first flew in limited commercial airline service in the 1970s (Spitzer, 2000) but finally, by the 1990s, the HUD advantages became cost-effective. One HUD manufacturer, Rockwell Collins (Flight Dynamics prior to 1998), now has 
more than 3,300 HUDs in service worldwide, certificated on 40 air transport category aircraft, including on a variety of executive jets built by Bombardier, Dassault, Gulfstream and Boeing (Croft, 2010). The HUD is becoming well ingrained in commercial aviation. The Boeing 787 is equipped with dual HUDs for the Captain and First Officer as standard equipment.

\subsection{HUD “Operational Credit”}

Thanks in part to the characteristics of the HUD, and in addition to safety benefits, "operational credits" are now being derived from HUD equipage.

These HUD-unique credits include:

- Fail-passive landing capability to 50-foot DH and RVR of 600-foot using HUD-driven guidance through approach, flare, landing, and roll-out (as per Federal Aviation Administration (FAA) Advisory Circular (AC)120-28D);

- Low visibility takeoff minima of $300 \mathrm{ft}$ RVR (as per AC120-28D);

- Special Category II minima on Type I ILS of 100-foot DH, 1,200-foot RVR (as per FAA Order 8400.13);

- Reduction in Category II minima to 1,000-foot RVR (as per FAA Order 8400.13); and

- Special Category I minima of 150-foot DH, 1400-foot RVR in lieu of centerline and touchdown zone lighting (as per FAA Order 8400.13).

Investigation by NASA and others is also being conducted for the possibility of operational credit (lower DH or reduced visibility minima) from the use of Synthetic Vision displayed on the HUD (Figure 1).

Also, the HUD is the only display currently certified and approved for use as an EFVS. With EFVS, a pilot may descend below the published decision altitude (DA) from a straight-in instrument approach using an EFVS (see Figure 1) in lieu of natural vision (as per Federal Aviation Regulation $§ 91.175$ (l) and (m)).

The EFVS operational credit (as per $\S 91.175$ (l) and (m)) explicitly expressed that the use of a HUD was an essential "characteristic and feature" of the EFVS operation. However, provisions for the use an equivalent display were made.

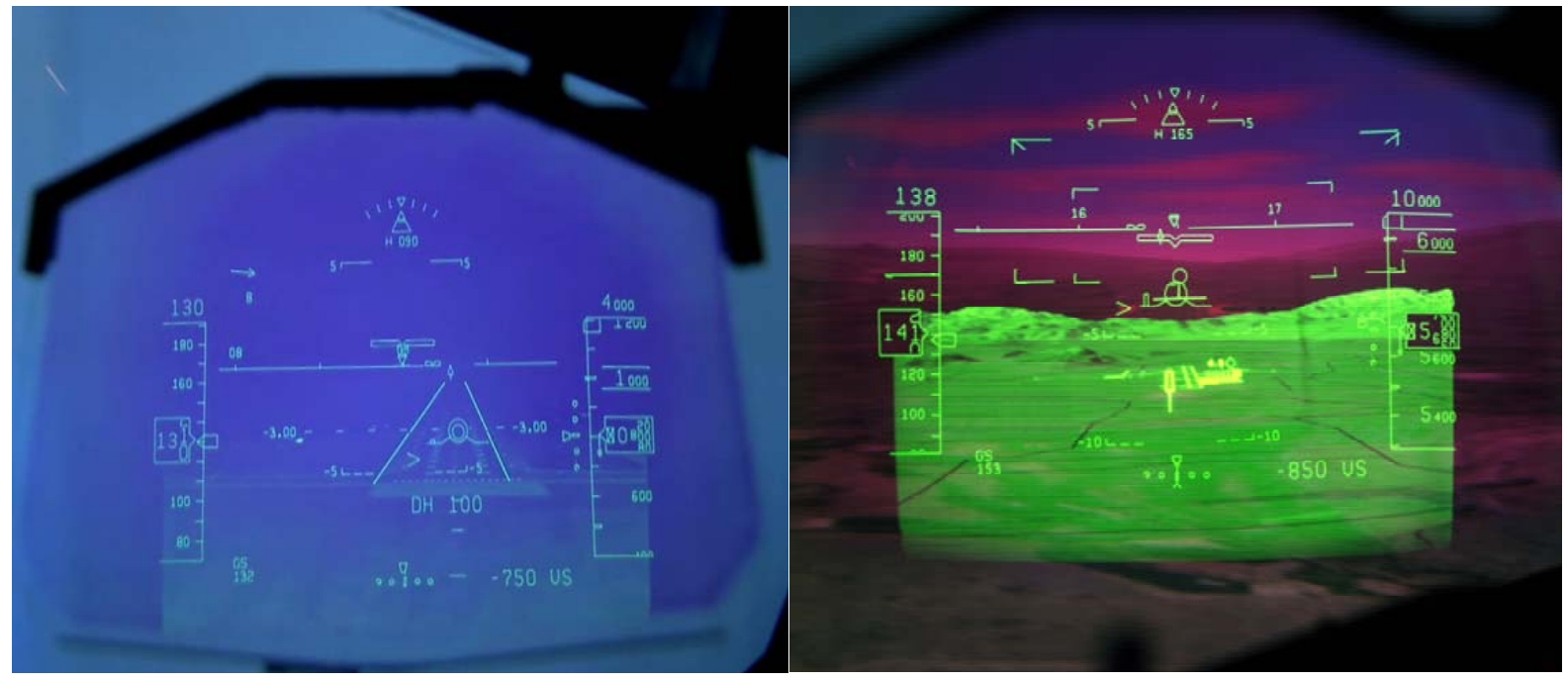

Figure 1. Enhanced Vision HUD (Upper Left), Synthetic Vision HUD (Upper Right)

What constitutes an equivalent display is not explicitly defined, but by inference, the display must present "the required features and characteristics such that they are clearly visible to the pilot flying in his or her normal position and line of vision looking forward along the flight path." A critical component of EFVS performance is the integration of the "visual-like" imagery with symbology where the imagery is a display of the external scene from an imaging sensor, such 
as a Forward-Looking InfraRed or millimeter wave radar. The primary reference for maneuvering the airplane is based on what the pilot sees through the EFVS and the conformal HUD symbology. As such, the required external visual references must be continuously and distinctly visible and identifiable by the pilot.

\subsection{HWD as a HUD Replacement}

With many operational credits being provided by HUD operations, one possible avenue of HWD injection is by providing a HUD-equivalent capability.

The requirements for a HWD to meet a "HUD-equivalent" capability may be derived from FAA guidance material. For instance, under EFVS operations, these "essential features" of the HUD or equivalent display were described as follows (Bailey, Kramer, and Williams, 2009):

- The display should provide the EV image and spatially-referenced flight symbology so that they are aligned with and scaled to the external view (i.e., conformal rendering).

- The display should be located so the pilot is looking forward along the flight path (i.e., looking at and through the imagery to the out-of-the window view) to readily enable a transition from EFVS imagery to the out-the window view.

- The display should not require the pilot to scan up and down between a head down display of the image and the out-the-window view looking for primary flight reference information. This transition would otherwise be hindered by repeatedly re-focusing from one view to the other.

These requirements suggest that an HUD-equivalent display must provide conformal imagery; therefore, the HWD must use head-tracking to create a "Virtual HUD" concept. The Virtual HUD concept is not new. The F-35 is working toward making the HWD a HUD replacement (Frey and Page, 2002). However, achieving this capability for business and commercial aircraft is a formidable challenge.

For commercial and business aircraft, three potential markets are evident for a HWD HUD-equivalent. These markets exist where:

- HUD installation is not possible or practical by volume or weight;

- HUD retro-fit is not cost-effective; and,

- HWD installation has a return-on-investment advantage to the HUD.

In many aircraft, a HUD installation is not possible or practical, principally from a volume standpoint. Current generation HUDs require a significant overhead volume for the projector. For this reason, many new aircraft and retrofit applications of a HUD are impossible or impractical because the aircraft doesn't have enough overhead space. This limitation is well-recognized and many avionics vendors are trying to develop new HUD technologies to overcome this limitation. For instance, the Micro-Vis ${ }^{\mathrm{TM}}$ by Kollsman and the Q-HUD ${ }^{\mathrm{TM}}$ by BAE Systems (Cameron, 2009) are adapting waveguide optics technologies to eliminate the HUD projector. The cost of the Micro-Vis HUD is also advertised to be an order of magnitude less expensive than a 'traditional' HUD, being around the $\$ 50,000$ price point, compared to $\$ 500,000$ for traditional overhead projection systems (Pope, 2006). The challenge for these new technologies - just like the HWD - is to meet the extremely high optical performance standards of current-day HUDs.

The HWD also presents a much easier installation and retro-fit path than a HUD. Since, by definition, the HWD must be lightweight and un-encumbering to the user, the installation does not require overhead hard-points from which to mount combiner glass and wiring harnesses for a HUD.

Not only does volume get into the factors influencing HWD introduction into commercial and business aviation, but the weight of current HUD systems is also a factor. Current overhead and combiner technologies can easily weight $25 \mathrm{lbs}$ or more. This weight is far greater than the desired $0.25 \mathrm{lbs}$ head-borne weight of the ideal HWD. The return-oninvestment by saving weight is obviously different for each operator, but one perspective is provided by American Airlines (http://www.aa.com/i18n/amrcorp/newsroom/fuel-smart.jsp). In their analysis, every pound removed from an aircraft can help save as much as 12,000 gallons of fuel annually fleet-wide. For this reason, American Airlines conducted significant weight-scrubs, including the removal of such unnecessary cabin items as old phone equipment, 
magazine racks and razor outlets. The possibility of saving $25 \mathrm{lbs}$ for each HUD-equipped aircraft might create a reasonable return on investment.

The primary technical challenge for a HUD-equivalent HWD is to create equivalent optical performance. One might also consider other factors such as those cited for the lack of acceptance of HWDs in consumer and military applications (Havig et al, 2009). In combination, these create a formidable obstacle and one which grows each day as HUD technology moves toward higher brightness, larger fields-of-view and greater resolutions. Where a $32 \mathrm{deg} \mathrm{H}$ x $24 \mathrm{deg} \mathrm{V}$ field-of-view HUD was state-of-the-art five years ago, active-matrix Liquid Crystal Display technology with lightemitting diodes backlighting now create a HUD that's $20 \%$ lighter than the previous generation with 1,400 x 1,050 pixels covering a horizontal range of 42 degrees and vertical swath of 30 degrees (Croft, 2010a). Brightness levels are also approaching that required for full daylight readability of SEVS imagery where the backlights are said to provide 4 shades of green at 10,000 ft-Lamberts (Bailey, 2002).

The potential market for HUDs (or HWD-equivalents) is big and getting bigger. HUDs are quickly becoming standard equipment on commercial transports, and Boeing predicts that the single-aisle fleet will double by 2029 and the twinaisle market will grow even more, from 3,500 airplanes in operation now, to 8,260 in 2029 (Boeing, 2010). Business aviation is traditionally the proving ground for advanced safety and efficiency technologies. Forecasts suggest that after bottoming out in 2009-2010 from 7,500 to 11,500 light, medium, and large/ultra-large business jets will be delivered in the next ten years (Bombardier, 2009; AOPA, 2009). If you consider that the "core market" for this technology might be small and medium business jets which cannot accommodate a traditional HUD, there are an estimated 8,700 aircraft deliveries expected from 2009 to 2019 (Bombardier, 2009). SEVS technologies are standard equipage on the flight deck of today's large/ultra-large business jets so the smaller business jets represent prime opportunity for HWD growth by providing HUD-equivalent and EFVS operational credits.

\section{NEW OPERATIONAL CONCEPTS AND CAPABILITIES}

HWDs for commercial and business aviation may also emerge by providing NextGen operational and safety capabilities that cannot be fulfilled by any other display device.

Back in the 1990s, NASA research to develop technologies to improve aircraft surface operations efficiency and safety led to the development of the Taxiway-Navigation and Situation Awareness (T-NASA) system (Foyle et al, 1996) and the Runway Incursion Prevention System (Jones et al, 2006). These systems showed the importance of taxiway awareness, route awareness, and taxi guidance on HUD and head-down displays to enable taxi times, approaching those achievable in VFR operations, and to prevent pilot error in surface operations, including missed taxi clearances, missed understanding of taxi instructions, making wrong turns, and becoming lost on the airport surface.

However, this research also noted that two of the major HUD limitations during ground operations were their monochrome form and limited, fixed field-of-view.

Two ground-based simulation experiments were subsequently conducted to evaluate if a HWD could provide benefits in performance and safety over a HUD during current-day aircraft surface operations at Chicago, O'Hare International Airport. The key HWD attributes evaluated in these experiments were: 1) HUD equivalence using a virtual HUD concept, to that provided as the T-NASA HUD; and, 2) off-boresight enhancements using the full field-of-regard potential of the HWD. The results showed that HUD and HWD were essentially equivalent, and a slight improvement was gained for the HWD in terms of surface traffic awareness, as measured under "rare event" conditions, due to the unlimited field-of-regard (Arthur et al, 2009).

Under NextGen, emerging surface operational concepts will create even more trying conditions. NextGen must accommodate increased traffic and surface operations can quickly become a choke-point, especially during low visibility conditions. Further, 4-D required time of arrivals are expected in surface routing, as part of the NextGen trajectorybased operations. The off-boresight, head-out capability of the HWD promises to be a key enabling technology for 4-D surface operations in NextGen (Bailey et al, 2011).

NASA is conducting RDT\&E of a "Better-Than-Visual" (BTV) operational capability. BTV operational capability builds from and expands the NextGen concept of EVO (Bailey et al, 2011). The BTV operational concept replicates the 
capacity of today's VFR operations and more importantly, meets and improves on the safety of today's VFR flight in allweather NextGen conditions. BTV is enabled by an electronic means of displaying intuitive visual references of the external world and other required flight references on flight deck displays. By providing VFR-like intuitive imagery to the pilot/flight crew, VFR-like operational tempos and VFR procedures are envisioned for all weather conditions. As a minimum, the excellent safety record of VFR operations is met and even improved upon by augmenting these displays to show the "invisible" safety hazards during actual VFR, such as clear air turbulence and wake vortices, and precise path control information to promote stabilized approach procedures.

This BTV operational concept (Figure 2) suggests that the minimum aviation system performance standard for BTV technologies should be that as defined by human performance in the same operation using windows during today's VFR operations. The concept implies that the HWD provides an electronically-generated view of the world, as if the pilot were looking outside the windows on a clear day. Significant research is required to quantify this hypothesized performance standard, and more importantly, to determine if this standard is indeed an appropriate and sufficient standard for BTV. If it is, the HWD, providing an unlimited field-of-regard, is a critical element to achieving this concept.

Further, the HWD provides:

1. Spatially-Integrated Display Concepts: Combinations of aircraft-reference and earth-reference symbology and imagery will create "spatially-integrated" display concepts where the location of the displayed information provides cueing information for the pilot. The technique of symbology scene-linking facilitates efficient cognitive processing may also mitigate problems of attentional tunneling (e.g., Foyle et al, 1995).

2. Reduced Clutter Visual Displays: A significant challenge in NextGen will be Net-Centric operations where each user of NextGen shares information to be better informed and make better decisions and actions. This wealth of information must be efficiently consumed and processed with appropriate and timely actions. The HWD can provide significant increased visual display area, thus, mitigating visual clutter. The entire three-dimensional volumetric space around the pilot can be used, as appropriate and necessary to off-load the visual channel. Binocular optics might also add the potential to use stereoptics for decluttering and more effective information presentation (Parrish, Williams, and Nold, 1994; Wickens, Todd, and Seidler, 1989; Reising and Mazur, 1990).

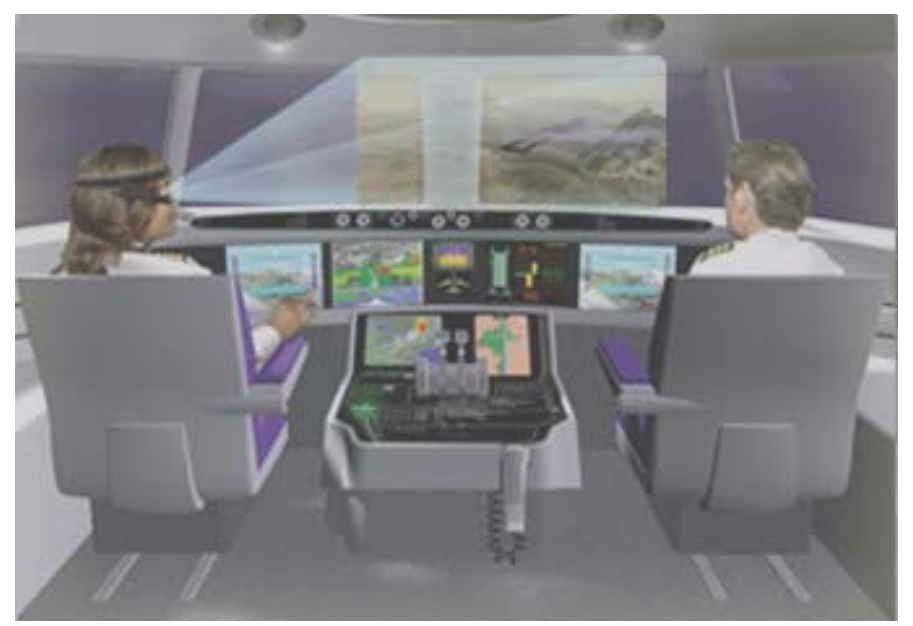

Figure 2: Notional BTV Flight Deck 


\section{TECHNICAL HURDLES AND EMERGING REQUIREMENTS FOR HWD APPLICATIONS}

The opportunities for HWD in commercial and business aviation, especially as NextGen operations emerge, seem significant. But two principle technical challenges are apparent:

1) User encumbrance

2) Equivalent HUD performance

\subsection{User Encumbrance}

Hard data are not available as to what level of encumbrance will be tolerable for the business and commercial aviation market with HMDs. In Havig et al, 2009, the authors cites equipment encumbrance as one of the barriers to HMD applications.

For military applications, HWDs have typically been an "add-on" to helmets that aviators already fly with. The challenge was to minimize the weight growth and the center-of-gravity shift for the helmet and HWD.

The assumption for the business and commercial aviation market has been the same - minimize the added weight and keep the shift in center-of-gravity minimal. The key difference is that in the business and commercial aviation, pilots don't wear a helmet. The concept, shown in Figure 3, assumes attachment to a lightweight headset. However, headsets are not always worn either. The goal should be to create an HWD which has no more weight or encumbrance than that of the current commercial and business aviator's only true equipage - sunglasses.

NASA has made selected investments into head-tracker (http://www.intersense.com/pages/27/74) and display technology development (http://sbir.gsfc.nasa.gov/SBIR/abstracts/10/sbir/phase1/SBIR-10-1-A1.05-9370.html) to miniaturize the HWD size and weight while striving to achieve the optical performance standards demanded for HUD-equivalent performance.

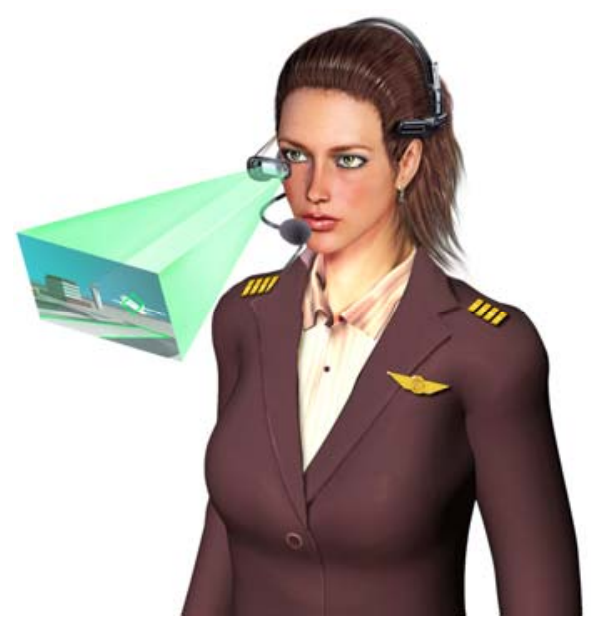

Figure 3: Commercial HWD Concept

\subsection{Equivalent HUD Performance}

As a minimum, a HWD should be expected to meet (or exceed) the optical performance characteristics defined for HUDs using SAE AS8055, "Minimum Performance Standard for Airborne Head Up Display (HUD)." and those characteristics identified in FAA Advisory Circular (AC) 25-11, "Transport Category Airplane Electronic Display Systems" related to HUDs. Using these standards, some derived requirements for HWDs are reviewed which pose particular technical challenges. 


\subsubsection{Head Tracking $\quad$ Hea}

To create a HUD-equivalent display levies some stringent requirements on head tracking performance for HWDs. A key performance aspect of the HUD from SAE AS8055 is that of symbol positioning accuracy. Additionally, requirements may be derived for boresighting and the integrity of the HWD accuracy levels. These requirements dictate static positioning (the combination of display optics errors and head-tracking positioning accuracy) and dynamic accuracy (i.e., latency).

The HUD requirement under SAE AS8055 for symbol positioning accuracy is: a) no more than 5.0 mrad error on boresight; b) no more than $7.5 \mathrm{mrad}$ when $\leq 10^{\circ}$ diameter around boresight; and c) no more than $10.0 \mathrm{mrad}$ when $\leq 30^{\circ}$ diameter around boresight. These allowable display accuracy errors are measured from the HUD Eye Reference Point.

Derived requirement for HWDs to be HUD-equivalent would be:

- The head-tracker (and display system errors) must provide a boresighted solution within 5 mrad.

- These HUD accuracy levels must be maintained whenever the HWD is located within the HUD eye box, centered at the cockpit design eye reference point with \pm 1.5 inches laterally, \pm 1.0 inch vertically, and \pm 2.0 inch longitudinally.

- Allowable display errors when outside this HWD/HUD eye box have not been identified.

- With a HUD, no "boresighting" is required, so for HUD-equivalence, the capability to achieve these performance levels without a boresighting procedure is ideal (e.g., see Luo et al, 2005).

- If a HUD combiner comes out of its detent (which degrades the HUD symbol position accuracy), a warning on the HUD is generated to alert the pilot. This same type of capability should annunciate to the pilot that the HWD is not currently aligned.

\subsubsection{Latency}

Head-tracker latency dictates the dynamic symbol /imagery positioning accuracy.

An end-to-end latency requirement of no more than $20 \mathrm{msec}$ has been proposed (e.g., Bailey et al, 2004) for Virtual HUD applications based on previous work (Frey and Page, 2002). However, the acceptable latency may become significantly smaller if dynamic stability is a driving requirement. SAE AS8055 standards suggest that this is the case.

SAE AS8055 specifies the maximum allowable error of $7.5 \mathrm{mrad}$ within $10^{\circ}$ diameter of boresight using 2-standard deviation (sigma) allowances. The data from (Arthur et al, 2007; Bailey et al, 2007) showed that the 2 standard deviation of azimuth rate of pilot's head movement was approximately $50 \mathrm{deg} / \mathrm{sec}$. If we use this value and impose that the accuracy for equivalent-HUD performance must be less than $7.5 \mathrm{mrad}(0.429 \mathrm{deg})$, the end-to-end system latency must be less than $10 \mathrm{msec}$ to achieve HUD-equivalent levels of dynamic system performance (i.e., $0.429 \mathrm{deg} / 50 \mathrm{deg} / \mathrm{sec}$ $\sim 9$ msec latency).

The technical challenge is that this allowable latency is an 'end-to-end' requirement. A basic HWD with head tracking system, from end-to-end, is comprised of: 1) a near-to-eye display, 2) the head tracking system, 3) one or more symbology or image sources, 4) and the display/image processor. Each element and the communication between them contribute a portion to the total latency (see Figure 4).

No commercial or standardized device is available to measure and quantify end-to-end latency. NASA has developed a prototype Head-worn display Latency Measurement Rig (HeLMR) for this purpose.

The HeLMR apparatus consists of an anatomically correct, human head which is able to 'wear' available commercial and custom HMD systems. A camera is installed in place of the eye(s) in the correct image plane location. The head is mounted on a precision rotary stage that moves the head in a left-right-left 'No-No' fashion at a precise angular rate (see Figure 4, Figure 5).

To measure the end-to-end latency, a space-stabilized symbol is rendered on the HWD along the boresight. As the head is slewed, the space-stabilized symbology becomes misaligned with respect to the outside reference, proportional to the end-to-end system latency and the headform angular rate. 


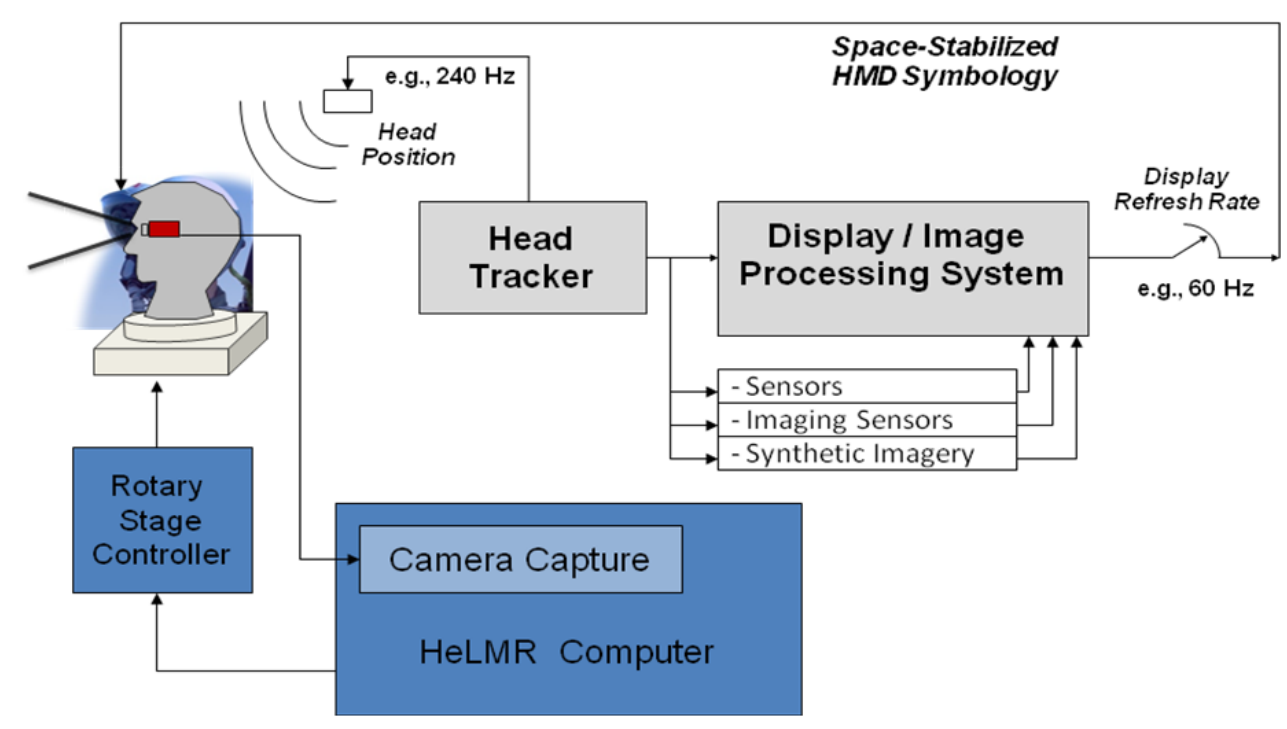

Figure 4: Typical Tracking HMD system

On the HeLMR development system, the space-stabilized symbology is viewed against a lateral graduated, calibrated scale. In-situ measurements don't require custom HWD programming to quantify latency. The head is moved and tracked dynamically. The high speed $\left(300^{+}\right.$frames per second) video image from the eye camera shows the angular skew of the virtual to actual image due to the system latency. An image is captured and the angular difference of the virtual to actual is measured. This image is captured manually or automatically and the angular offset can be manually determined or automatically determined using image processing software. The end-to-end latency is calculated by dividing the measured angular displacement by the precise rate the rotary stage is moving (Figure 6).

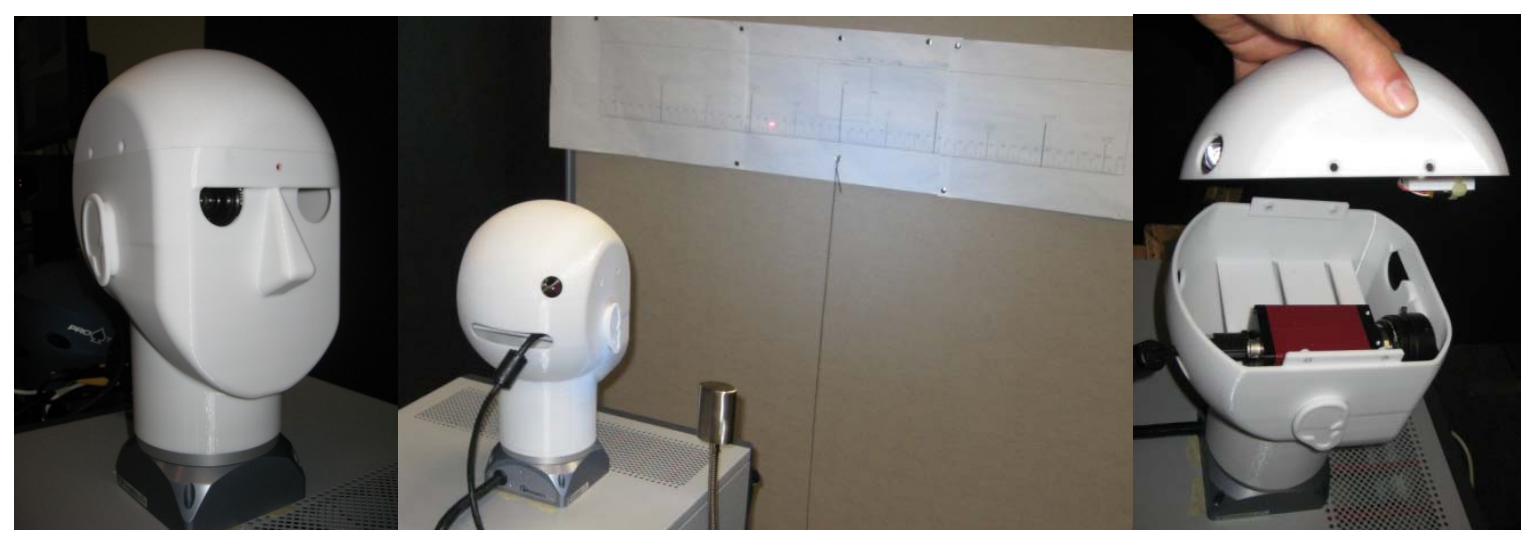

Figure 5: HeLMR System (Head, Camera, Rotary Stage, Stage Controller, DC Light Source\} 


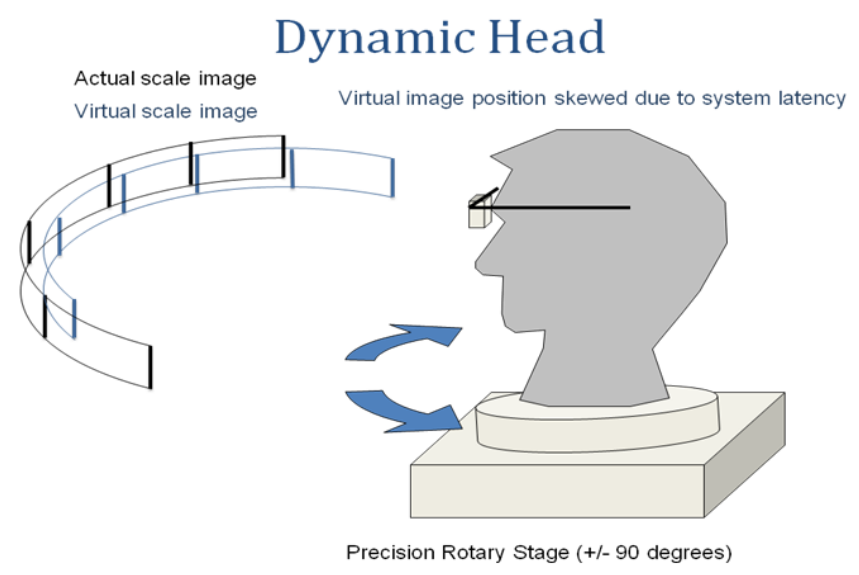

Figure 6: Eye Camera Image Of Both Scales With A Moving Head

A prototype Rockwell Collins ProViewTM SO35-MTV21 coupled with a modified Intersense, Inc IS-1200 tracker was used to render an integrated synthetic terrain and virtual HUD. The total system latency of the HWD system was measured to be 67 milliseconds. To identify the predominant latent elements, the end-to-end system latency was measured again but this time without the synthetic terrain being rendered. In this case, the latency dropped to 33 milliseconds - indicative of the $30 \mathrm{~Hz}$ frame rate terrain rendering process.

These data show that the use of vision system technology on the HWD introduces significant latency and even without it, more work is needed to reduce the latency to acceptable levels. Software and hardware methods to attain 10 to $20 \mathrm{msec}$ latency are needed.

\subsubsection{Field-of-View}

In Havig et al (2009), a field-of-view requirement of 120 degrees horizontal by 50 degrees vertical was proposed for commercial and military applications. If possible (with no less resolution in terms of pixels per degree than provided by today's traditional HUD), this HWD field-of-view should be clearly adequate.

Most HUD requirements suggest 20 degrees (horizontal and vertical) are the minimum acceptable. Recent research in a vertical landing task (non-fixed wing) suggests that the $29 \mathrm{deg} \mathrm{H} \mathrm{x} 22 \mathrm{deg} \mathrm{V}$ field-of-view was not sufficient (Arthur et al, 2010). Firm FOV requirements in commercial and business market are not available, but greater than 30 deg FOV looks like a certainty and 120 deg H FOV would be a desirable FOV objective.

\subsubsection{Clutter and Obscuration}

The HWD provides a unique challenge during surface operations as display clutter and obscuration becomes critical.

In low visibility flight conditions (i.e., in visibility less than $2400 \mathrm{ft}$ ), the out-the-window view is essentially obscured. However, once in the flare and on the surface, this out-the-window visibility becomes extremely critical, no matter how limited it might be. The concept of zero-zero (i.e., zero visibility and zero ceiling) just does not practically occur. In actuality, some usable visibility is available.

The available out-the-window visibility provides the 'truth' and at least one pilot is always head-out during the flare and during surface operations. The HUD or HWD must be designed to augment the prevailing visibility - providing sufficient information to enhance or enable the operation - without significantly obscuring it. Today, HUDs are certified only after demonstrating that they are in compliance with Part 14 of the Code of Federal Regulations $\$ 25.773$, showing that the HUD design still gives the pilots "a sufficiently extensive, clear, and undistorted view, to enable them to safely perform any maneuvers within the operating limitations of the airplane, including taxiing takeoff, approach, and landing." 
For a HUD, only the forward view is affected by the HUD information. The pilot can always look around the HUD to see an unobscured view forward of the aircraft. Also, the use of a "de-cluttering" function is required for the express purpose "to enhance pilot performance" under AC25-11. Minimum aviation system performance standards for EFVS and SV (RTCA DO-315) includes requirement such that "a control shall be provided which permits the pilot flying to deactivate and reactivate the display of the EFVS image on demand without removing the pilot's hands from the primary flight controls (yoke or equivalent) and thrust control."

Unlike the HUD, the HWD creates an unlimited field-of-regard informational capability, but it also may create additional clutter or obscuration above and beyond what the HUD may provide.

Three possible methodologies are being investigated to mitigate unwarranted HWD clutter or obscuration:

1. Automatic and manual HWD declutter: The HWD symbology and imagery may be designed with automatic and pilot-activated decluttering to minimize clutter or obscuration, mimicking current HUD concepts. For instance, HWD symbology and imagery 'cut-outs' are applied so whenever the pilot is looking inside the cockpit, the HWD symbology and imagery located within the cockpit are blanked. This creates an clear HWD view so the pilot can look inside with cockpit without having HWD information obscuring or cluttering the view. If the pilot wants to use the head-referenced HWD imagery or symbology when looking into the cockpit (e.g., they want to see information passing under the aircraft), a 'dead-man' switch is used to inhibit the HWD cut-out. In addition, a hands-on stick or throttle switch can clear the imagery or symbology (or both) on the HWD whenever the pilot wants or needs to have a clear view through the HWD. The challenge would be if this combination of automatic and manual declutter of the HWD would be sufficient to meet the $\$ 25.773$ requirement, as well as the functional/task requirements without increasing pilot workload. Research is needed to address if these requirements change for a monocular vs. biocular HWD. Biocular rivalry issues obviously become important as well and may create an interaction. Research has started to address some of these issues (Valimont, 2009).

2. "Semi-Conformal": Instead of positioning the HWD directly in front of the pilot's eyes, NASA has conducted cursory investigation of "semi-conformal" concepts (Arthur et al, 2009) which can provide conformal information without outside visibility obscuration (see Figure 7). In the semi-conformal concept, the HWD is angled slightly above the 'boresight' of the pilot's normal forward view. The pilot could look up to see the information, or to see the HWD information, with conformal overlay on the out-the-window view, the pilot must slightly rotate their head. In effect, the pilot makes a head-movement to bring the information into their view which, in essence, is the pilot's 'switch' to modulate the presence or absence of HWD information. The key element is that the HWD does not nominally interfere with a pilot's normal vision.

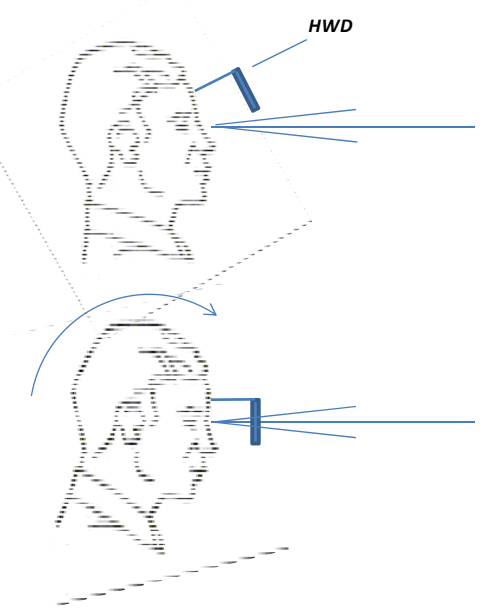

Figure 7: Illustration of 'Semi-Conformal” Concept 
3. "Beyond RVR" Control: The last concept being investigated attempts to create an intelligent declutter control (Figure 8). The HWD presentation is tailored knowing the natural visibility limitations (e.g., the prevailing visibility or RVR). In this case, earth-referenced data is not drawn knowing that the 'real-world' can be seen up to the prevailing visibility (i.e., the RVR). Beyond that range, where atmospheric conditions occlude the realworld, so earth-referenced data can be fully populated, such as SEVS technologies, knowing that it won't obscure any of the pilot's visibility of the real-world. Within the prevailing visibility, a very minimal set of screen- and aircraft-referenced data is drawn, only sufficient to meet the informational demands of the task.

Modulation of the clutter and obscuration of the pilot's view has the potential to be 'show-stoppers' for certification. Data are needed to support regulatory and design guidance for effective introduction of HWDs.

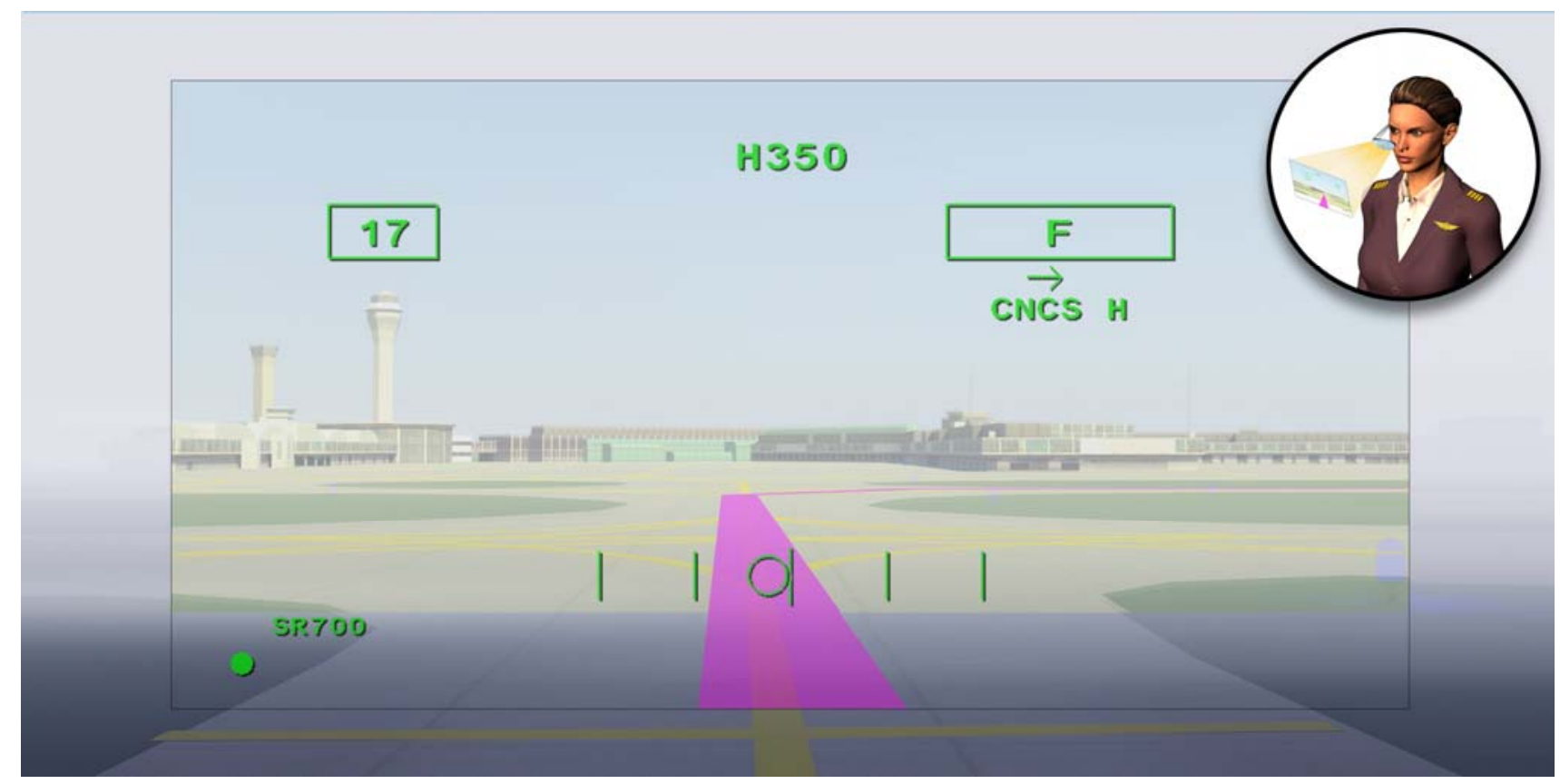

Figure 8: Hypothetical “Beyond RVR” HWD Display

\subsubsection{Accommodation and Vision Correction}

A key element providing operational credit for HUD usage is derived in the pilot's ability to use the head-up imagery while simultaneously looking forward along the flight path (i.e., looking at and through the imagery to the out-of-the window view) to readily enable a transition from EFVS imagery to the out-the window view. The transition by the pilot from using head-up display information to out-the-window references cannot be hindered or require re-focusing from one view to the other.

When using HUDs or other virtual displays such as HWDs, accommodation and cognition are influenced by numerous complex and interacting 'virtual display' factors. Research has shown sometimes contradictory findings (Edgar, 2007) as to how the HUD or other virtual display positively or negatively impact accommodation and cognitive switching. These data must be reexamined for HWDs. These influences likely interact with the type of HWD decluttering mechanisms are being used.

Further, the usability of the HWD, unlike a HUD, is more critically influenced by the user's age and their attendant vision corrections/deficiencies. Whereas the optical design of the HUD can provide a fairly significant eyebox, focused near infinity, the HWD may have a much smaller exit pupil which may play havoc on a pilot who normally 
needs eye glasses, including bi-focals and tri-focals. Commercial and business aircraft aviators become adept at using small eye movements to view head-down instruments while keeping their head up to use the HUD. This user population is a vastly different age demographic than the military Helmet-Mounted Display (HMD) community and its associated research data. Airline pilots can now fly to the age of 65 - very different than a military HMD aviator who, if they are lucky enough to still be flying at the end of their career, typically retire in their early 40 s.

\section{CONCLUDING REMARKS}

A head-worn display concept, coupled with a head tracker, has significant potential for NextGen, both in terms of creating a HUD-equivalent capability for aircraft that can't fit or afford a HUD or in terms of new operational or safety capabilities that might otherwise constrain the realization of NextGen.

Top-level technical hurdles for acceptable commercial and business HWDs have been identified. Some performance requirements have been identified based on HUD-equivalent capabilities. Research in the coming years will hopefully provide evidence for the validity of these requirements to support effective regulatory and technical development decision-making. Light-weight display and robust tracking technologies are needed to drive the state-of-the-art toward meeting these goals.

\section{REFERENCES}

AOPA. Honeywell Predicts a 2010 Bottom. http://www.aopa.org/nbaa/091019honeywell.html. Aircraft Owners and Pilot's Association, AOPA. 2009.

Arthur, J.J., Prinzel, L.J., III, Shelton, K.J., Kramer, L.J., Williams, S.P., Bailey, R.E., and Norman, R.M.: Synthetic Vision Enhanced Surface Operations With Head-Worn Display for Commercial Aircraft. The International Journal Of Aviation Psychology, Vol. 19, No. 2, April-June 2009. pp. 158-181.

Arthur, J.J., Bailey, R.E., Jackson, E.B., Barnes, J.R., Williams, S.P., and Kramer, L.J.: Part-task simulation of synthetic and enhanced vision concepts for lunar landing. In Proceedings of SPIE, Enhanced and Synthetic Vision 2010, Eds: Jeff J. Güell; Kenneth L. Bernier, Vol. 7689, April 2010.

Arthur, J.J., et al: Design and testing of an unlimited field-of-regard synthetic vision head-worn display for commercial aircraft surface operations. In Proceedings of SPIE, Enhanced and Synthetic Vision 2007, Ed. Jacques G. Verly, Jeff J. Guell. Vol. 6559, Orlando, FL, April 2007.

Bailey, R.E., Parrish, R.V., Kramer, L.J., Harrah, S.D., and Arthur, J.J. (Trey) III: Technical Challenges In the Development of a NASA Synthetic Vision System Concept. Paper presented at the RTO SET Workshop on "Enhanced and Synthetic Vision System," Ottawa, Canada, September 2002, published as NATO RTO-MP-107.

Bailey, R.E., Kramer, L.J., and Prinzel, L.J., III: Fusion of Synthetic and Enhanced Vision for All-Weather Commercial Aviation Operations (NATO RTO-HFM-141). NATO Human Factors and Medicine Symposium on Human Factors and Medical Aspects of Day/Night All Weather Operations: Current Issues and Future Challenges, 11-1 through 1118. April 2007.

Bailey, R.E.,. Arthur, J.E., and Williams,, S.P.: Latency Requirements for Head-Worn Display S/EVS Applications. In Proceedings of SPIE, Enhanced and Synthetic Vision 2004, Editors: Jacques G. Verly, Volume 5424, Apr 2004, pp. 98-109.

Bailey, R.E., Arthur, J.J. III, Williams, S.P., and Kramer, L.J.: Latency in Visionic Systems: Test Methods and Requirements. Presented at the RTO HFM Workshop on "Toward Recommended Methods for Testing and Evaluation of EV and E/SV Based Visionic Devices,", Williamsburg, Virginia, April 2004, published as NATO RTO-MP-HFM-125.

Bailey, R.E.,. Arthur, J.J., Prinzel, L.J., and Kramer, L.J.: Evaluation of head-worn display concepts for commercial aircraft taxi operations. In Proceedings of SPIE, Head- and Helmet-Mounted Displays XII: Design and Applications, Eds: Randall W. Brown, Colin E. Reese, Peter L. Marasco, Thomas H. Harding. Orlando, FL, Vol. 6557, May 2007.

Bailey, R.E.,. Kramer, L.J., and Williams,, S.P.: Enhanced Vision for All-Weather Operations under NextGen. In Proceedings of SPIE, Enhanced and Synthetic Vision 2010, Eds: Jeff J. Güell; Kenneth L. Bernier, Orlando, FL, Apr 2010. 
Bailey, R.E., Prinzel, L.J., Kramer, L.J., and Young, S.D.: Concept of Operations for Integrated Intelligent Flight Deck Displays and Decision Support Technologies. NASA Langley Research Center, NASA TM in press, Hampton, VA. Feb. 2011.

Boeing. Current Market Outlook, 2010-2029. Boeing Commercial Airplanes. Seattle, WA. 2010.

Bombardier. Leading the Way. Bombardier Business Aircraft Market Forecast 2009-2018. Bombardier Aerospace Corporation, 2009.

Cameron, A.A.: The Application of Holographic Optical Waveguide Technology to Q-Sight ${ }^{\mathrm{TM}}$ Family of Helmet Mounted Displays. In Proceedings of SPIE Head- and Helmet-Mounted Displays XIV: Design and Applications, Eds: Peter L. Marasco; Paul R. Havig; Sion A. Jennings; Thomas H. Harding. Volume 7326, Orlando, FL. 2009.

Chin, D.K. Goldberg, J., and Tang, T. (1997). Airport Surface Delays and Causes: A Preliminary Analysis. NASA Contractor Report 201721, August 1997

Croft, J.: EBACE: Rockwell Collins: hold your head up. Flight International. 26 April 2010.

Edgar, G.K. (2007): Accommodation, cognition, and virtual image displays: A review of literature. Displays, Vol. 28, 2007, pp. 45-59.

FAA (2009). Airport Capacity and Delay, US Department of Transportation, Federal Aviation Administration (FAA), AC150/5060-5, Washington, DC, 1983.

FAA (2009). FAA's NextGen - Implementation Plan, US Department of Transportation, Washington, DC, 2009.

Flight Safety Foundation (2009): Head-Up Guidance System Technology - A Clear Path to Increasing Safety. November 2009.

Foyle, D.C., McCann, R.S., \& Shelden, S.G.: Attentional Issues With Superimposed Symbology: Formats For SceneLinked Displays. In R.S. Jensen \& L.A. Rakovan (Eds.), Proceedings of the 8th International Symposium on Aviation Psychology, 8, 98-103. Columbus, OH: Ohio State University.

Foyle, D.C., Andre, A.D., McCann, R.S., Wenzel, E., Begault, D. and Battiste, V. Taxiway Navigation and Situation Awareness (T-NASA) System: Problem, Design Philosophy, and Description of an Integrated Display Suite for LowVisibility Airport Surface Operations. SAE Transactions: Journal of Aerospace, 105, 1996. pp. 1411-1418.

Frey, T.W. and Page, H.J.: Virtual HUD using an HMD. In Proceedings of SPIE Helmet- and Head-Mounted Displays VI, Eds: Ronald J. Lewandowski; Loran A. Haworth; Henry J. Girolamo; Clarence E. Rash. Volume 4361, Orlando, FL, 2001. pp. 251-262

Havig P.R., Goff, C., McIntire, J., and Franck, D.: Helmet-mounted displays: why haven't they taken off? In Proceedings of SPIE Head- and Helmet-Mounted Displays XIV: Design and Applications, Eds: Peter L. Marasco; Paul R. Havig; Sion A. Jennings; Thomas H. Harding. Volume 7326, Orlando, FL. 2009.

JPDO. NextGen Avionics Roadmap. Joint Planning and Development Office (JPDO), Version 1.0, 24 October 2008.

Jones, D.R., Quach, C.C., and Young, S.D.: Runway Incursion Prevention System - Demonstration and Testing at the Dallas/Fort Worth International Airport. Proceedings of the 20th Digital Avionics Systems Conference. Oct 2006.

Kramer, L.J., Williams, S. P., and Bailey, R.E.: Simulation evaluation of synthetic vision as an enabling technology for equivalent visual operations. In Proceedings of SPIE Enhanced and Synthetic Vision Conference 2008, 6957, 69570K-1-69570K-15.

Kramer, L.J., Bailey, R.E., Ellis, K.K.E., Norman, R.M., Williams, S.P., Arthur III, J.J., Shelton, K.J., and Prinzel III, L.J.: Enhanced and Synthetic Vision for Terminal Maneuvering Area NextGen Operations. SPIE Enhanced and Synthetic Vision Conference 2011, in press.

Luo, G., Rensing, N., Weststrate, E., and Peli, E.: Registration of an on-axis see-through head-mounted display and camera system. Optical Engineering, Vol. 44, No. 2, February 2005, pp. 024002-1-024002-7

Parrish, R.V., Williams, S.P., and Nold, D.E.: Effective Declutter of Complex Flight Displays Using Sterooptic 3-D Cueing. NASA Technical Paper 3426, April 1994.

Pope, S.: The Future of Head-Up Display Technology. Aviation International News, AINonline. 1 January 2006.

Reising, J.M. and Mazur, K.M. (1990). 3-D Displays for Cockpits: Where's The Pay-Off? Proceedings of SPIE, Stereoscopic Displays and Applications, Volume 1256, pp. 35-43, April 1990. 
Rustenburg, J.W., Tipps, D.O., and Skinn, D. A Comparison of Landing Parameters from Manual and Automatic Landings of Airbus A-320 Aircraft. University of Dayton Research Institute Technical Report UDR-TM-200100003, Nov. 2001.

The Avionics Handbook. Eds: Cary Sptizer. CRC Press, Boca Ratan, FL, USA. 2000.

Valimont, B., Wise, J.A., Nichols, T., Best, C., Suddreth, J., and Cupero, F.: When the wheels touch Earth and the flight is through, pilots find one eye is better than two. In Proceedings of SPIE Head- and Helmet-Mounted Displays XIV: Design and Applications, Eds: Peter L. Marasco; Paul R. Havig; Sion A. Jennings; Thomas H. Harding, Vol. 7326, Orlando, FL, April 2009.

Vasquez-Marquez, A.: American Airlines Arrival Slot Allocation System. Interfaces. Vol. 21, Jan-Feb 1991. pp. $42-61$.

Wickens, C.D., Todd, S., and Seidler, K. (1989). Three-Dimensional Displays: Perception, Implementation, Applications. Crew System Ergonomics Information Analysis Center, State of the Art Report, University of Illinois, October 1989. 